\title{
Prevalence of Human Cytomegalovirus and Epstein-Barr Virus in Chronic Periapical Lesions
}

\author{
Jelena Popovic ${ }^{\mathrm{a}}$ Jovanka Gasic ${ }^{\mathrm{a}}$ Slavoljub Zivkovic ${ }^{\mathrm{c}}$ Ljiljana Kesic $^{\mathrm{b}}$ \\ Aleksandar Mitic ${ }^{a}$ Marija Nikolic ${ }^{a}$ Jelena Milasin ${ }^{d}$ \\ Departments of a Restorative Dentistry and Endodontics and ${ }^{b}$ Oral Medicine and Periodontology, Clinic of \\ Dentistry, Medical Faculty, University of Nis, Nis, and Departments of ${ }^{C}$ Restorative Dentistry and Endodontics and \\ ${ }^{\mathrm{d}}$ Human Genetics, Faculty of Dentistry, University of Belgrade, Belgrade, Serbia
}

\section{Key Words}

Human cytomegalovirus · Epstein-Barr virus · Periapical lesions · Polymerase chain reaction

\begin{abstract}
Objective: The aim of this study was to investigate the presence of human cytomegalovirus (HCMV) and Epstein-Barr virus (EBV) in the tissue of chronic periapical lesions, and to compare the results in relation to the symptoms of patients and the size of the lesion. Methods: Periapical lesions analyzed in the study were collected from the roots of the teeth indicated for extraction. Samples were divided according to the symptoms into groups of symptomatic and asymptomatic, and according the size into groups of small and large lesions. Polymerase chain reaction was used to detect HCMV and EBV. The amplification was performed in a DNA Thermal Cycler (Hybaid). Results: Symptomatic lesions were 7.68 times more likely to be infected with HCMV than asymptomatic lesions $(p<0.001)$. Large symptomatic lesions were 73.50 times more likely to harbor HCMV than small symptomatic lesions $(p<0.001)$. Large symptomatic lesions were 7.64 times more likely to be infected with EBV than small symptomatic lesions $(p=0.05)$. Large symptomatic lesions
\end{abstract}

were 5.38 times more likely to harbor dual HCMV/EBV infection than small symptomatic lesions $(p=0.115)$. Conclusion: Detection of HCMV and EBV in the samples of periapical lesions suggests an important role of herpesviruses in periapical tissue destruction.

(c) 2015 S. Karger AG, Basel

\section{Introduction}

Periapical lesions are inflammatory immune diseases affecting the periapical tissues of the teeth and surrounding bone. These processes are primarily caused by polymicrobial bacterial infection from the root canal, with a predominance of Gram-negative anaerobic bacteria. Their maintenance, progression into chronic lesions and destruction of bone structures are the result of the host defense's inability to eliminate the infection $[1,2]$. Periapical lesions are histologically characterized by fibrous and granulomatous tissue, proliferating epithelium, or cyst infiltrated by various inflammatory cells [3-6].

Although apical periodontitis is generally asymptomatic, acute exacerbations occur relatively frequently and are associated with the intensification of clinical symp-

\section{KARGER 125}

(C) 2015 S. Karger AG, Base

0300-5526/15/0585-0271\$39.50/0

E-Mail karger@karger.com

www.karger.com/int
Jelena Popovic

Clinic of Dentistry, Medical Faculty, University of Nis

Blv. Dr Zorana Djindjica 52

RS-18000 Nis (Serbia)

E-Mail jelenadp@gmail.com 
toms $[1,2]$. The role of polymicrobial bacterial flora is well known in the pathogenesis of chronic periapical lesions. However, studies have also shown the involvement of herpesviruses, in particular human cytomegalovirus (HCMV) and Epstein-Barr virus (EBV), in periapical lesions [7]. Latent HCMV is present in periodontal macrophages and T lymphocytes, while latent EBV is present in periodontal B lymphocytes and epithelial cells of infected patients $[8,9]$. During acute exacerbations there is a new wave of cross-inflammatory cells that can carry latent herpesviruses. An inflammatory environment coupled with local bacteria can cause the activation of herpesviruses. Herpesvirus infection may enhance the production of proinflammatory cytokines leading to immunosuppression and immunomediated periapical tissue destruction [10].

The molecular method most often used for microbial identification is the polymerase chain reaction (PCR) method and its variations. The PCR method has been used in many investigations to provide additional valuable information regarding the identification and understanding of the causative factors associated with endodontic diseases, and may contribute to the development of improved treatment strategies [11].

The aim of this study was to investigate the presence of HCMV and EBV in the tissue of periapical lesions using PCR, and to compare the obtained results in relation to the symptoms of patients and the size of the lesion.

\section{Materials and Methods}

The study included 60 adult patients ( 33 males and 27 females; age range: $27-58$ years, average age: 43 ) from the Clinic of Dentistry, Medical Faculty, University of Nis, Serbia. Each patient had a clinically and radiographically diagnosed chronic periapical lesion. The study was approved by the Ethical Committee of the Medical Faculty, University of Nis, Serbia.

Periapical lesions analyzed in the study were collected from the roots of the teeth indicated for extraction. None of the cases demonstrated a moderate or severe type of marginal periodontitis. Periapical lesions were divided according to the symptoms into two groups: symptomatic and asymptomatic. Symptoms included swelling, pain, biting discomfort, or percussion and palpation sensitivity. According to their size, periapical lesions were divided into two groups: small ( $\leq 5 \mathrm{~mm}$ ) and large $(\geq 6 \mathrm{~mm})$. In order to establish the correct sample size, the measuring of the lesions was performed before tooth extraction on the radiographs and again after tooth extraction.

Prior to administration of local anesthetics, the teeth, gingiva and surrounding mucosa were washed with $0.12 \%$ chlorhexidine gluconate, and patients rinsed their mouth with chlorhexidine mouthwash for $30 \mathrm{~s}$. The samples of periapical lesions were taken immediately after teeth extractions, rinsed in sterile saline solu- tion, dried on sterile paper, placed in sterile plastic vial and immediately frozen at $-70^{\circ}$.

PCR was used to detect HCMV and EBV. The samples of periapical lesions were unfrozen before PCR analysis. For the purpose of DNA extraction, each sample was immersed in $200 \mu \mathrm{l}$ of physiological buffer with $7 \mu$ l of proteinase $K$. The samples were incubated for $15 \mathrm{~min}$ at $55^{\circ}$, and then boiled for $10 \mathrm{~min}$ to inactivate proteinase $\mathrm{K}$. The material was pelleted by centrifugation and the supernatants were transferred into clean tubes and stored at $-20^{\circ}$ until PCR analysis.

PCR was performed in volumes of $25 \mu \mathrm{l}$ PCR buffer, $200 \mu \mathrm{M}$ of each dNTP, $20 \mathrm{nM}$ of primer, $1 \times$ buffer $(10 \mathrm{mM}$ of $\mathrm{KCl}$ and $50 \mathrm{~mm}$ of Tris- $\mathrm{HCl}$ ), $3 \mathrm{mM}$ of $\mathrm{MgCl}, 1.5 \mathrm{U}$ of Taq DNA polymerase and $3 \mu \mathrm{l}$ of DNA-containing supernatant.

The amplification was performed in a DNA Thermal Cycler (Hybaid).

\section{Amplification of the HCMV-Specific Gene Sequence}

Initial denaturation of DNA was performed at $94^{\circ}$ for $3 \mathrm{~min}$, followed by 30 cycles of denaturation at $94^{\circ}$, annealing at $56^{\circ}$ and elongation at $72^{\circ}, 30 \mathrm{~s}$ each. Final extension was performed at $72^{\circ}$ for $5 \mathrm{~min}$.

\section{Amplification of the EBV-Specific Gene Sequence}

Initial denaturation of DNA was performed at $94^{\circ}$ for $10 \mathrm{~min}$, followed by $1 \mathrm{~min}$ and $30 \mathrm{~s}$ of denaturation at $94^{\circ}$, annealing at $60^{\circ}$ for $45 \mathrm{~s}$, elongation at $72^{\circ}, 2 \mathrm{~min}$ in 35 cycles. Final extension was performed at $72^{\circ}$ for $10 \mathrm{~min}$.

Twenty microliters of amplification mixture were subjected to electrophoresis in $8 \%$ polyacrylamide gel $(20 \mathrm{~V} / \mathrm{cm}$ in Tris-borate EDTA buffer), containing $0.5 \% \mu \mathrm{l} / \mathrm{ml}$ ethidium bromide. Amplified fragments were visualized under ultraviolet transilluminator. The result was considered to be positive if a band of expected size was present. Lymphoid cell lines containing HCMV and EBV were used as positive controls, while a PCR mixture containing $3 \mu \mathrm{l}$ of distilled water instead of sample was used as a negative control. Details on the sensitivity and specificity of the sets of primers have been described previously [12-14]. Primer sequences and product lengths are given in table 1.

Statistical analysis was carried out using the nonparametric $\chi^{2}$ test. The likelihood of herpesviruses in symptomatic periapical lesions versus asymptomatic and large lesions versus small was expressed as an odds ratio (OR) and relative risk (RR). Statistical significance was set at $\mathrm{p}<0.05$.

\section{Results}

From a total of 60 lesions examined, 31 belonged to the symptomatic group (23 large and 8 small) and 29 belonged to the group of asymptomatic lesions (18 large and 11 small).

\section{Qualitative PCR Outcome}

A higher occurrence of HCMV infection was present in symptomatic lesions compared to asymptomatic. PCR analysis showed that 22 of 31 (70.96\%) symptom- 
Table 1. PCR primers for HCMV and EBV

\begin{tabular}{lll}
\hline Target & PCR primers & $\begin{array}{l}\text { Size of amplicon, } \\
\text { base pairs }\end{array}$ \\
\hline $\begin{array}{l}\text { HCMV } \\
\text { Forward primer } \\
\text { Reverse primer }\end{array}$ & $5^{\prime}$-CCACCCGTGGTGCCAGCTCC-3' & 159 \\
EBV & $5^{\prime}$-CCCGCTCCTCCTGAGCACCC-3' & \\
$\begin{array}{l}\text { Forward primer } \\
\text { Reverse primer }\end{array}$ & $5^{\prime}$-CTCCCGCACCCTCAACAAGCTA-3' & \\
\hline
\end{tabular}

atic lesions, and only 7 of 29 (21.13\%) asymptomatic lesions were HCMV positive $\left(\chi^{2}=13.16\right.$; $\mathrm{p}<0.001$; table 2). Analysis with respect to the size showed that 21 of $23(91.30 \%)$ large symptomatic lesions were HCMV positive, while only 1 of 8 (12.5\%) small symptomatic lesions harbored HCMV $\left(\chi^{2}=17.89 ; \mathrm{p}<0.001\right.$; table 3$)$. Within the group of asymptomatic lesions, 7 of 18 (38.88\%) large lesions were HCMV positive, whereas all small lesions were HCMV negative $\left(\chi^{2}=5.64 ; \mathrm{p}<0.05\right.$; table 4).

PCR analysis of EBV showed that 13 of 31 (41.93\%) symptomatic lesions were EBV positive, and all asymptomatic lesions were EBV negative $\left(\chi^{2}=15.53 ; \mathrm{p}<0.001\right.$; table 2). In relation to the size, 12 of 23 (52.17\%) large symptomatic lesions were EBV positive, while 1 of 8 (12.5\%) small symptomatic lesions was EBV positive $\left(\chi^{2}=3.04 ; p=0.05\right.$; table 3$)$.

$\mathrm{HCMV} / \mathrm{EBV}$ dual infection was observed in 11 (35.48\%) of 31 symptomatic lesions, whereas none of 29 asymptomatic lesions showed dual infection $\left(\chi^{2}=12.6\right.$; $\mathrm{p}<0.001$; table 2$)$. In relation to the size, 10 of $23(43.48 \%)$ large symptomatic lesions had dual HCMV/EBV infection, and 1 of $8(12.5 \%)$ small symptomatic lesions was HCMV/EBV positive $\left(\chi^{2}=2.49 ; \mathrm{p}=0.115\right.$; table 3$)$.

\section{Risk Assessment}

The OR of symptomatic lesions harboring HCMV was 7.68 times higher than asymptomatic lesions $(\mathrm{p}<0.001$; 95\% CI: 2.43-24.29; table 2). Large symptomatic lesions were 73.50 times more likely to harbor HCMV than small symptomatic lesions ( $\mathrm{p}<0.001$; 95\% CI: 5.75-939.78). Large symptomatic lesions were 7.64 times more likely to be infected with EBV than small symptomatic lesions ( $\mathrm{p}=0.05$; 95\% CI: 0.81-72.41). Large symptomatic lesions were 5.38 times more likely to harbor dual HCMV/ EBV infection than small symptomatic lesions $(\mathrm{p}=0.115$; 95\% CI: 0.57-51.17; table 3).
Table 2. PCR herpesvirus detection in symptomatic and asymptomatic lesions

\begin{tabular}{llllll}
\hline Herpesvirus & $\begin{array}{l}\text { Symptomatic } \\
\text { lesions }(\mathrm{n}=31)\end{array}$ & $\begin{array}{l}\text { Asymptomatic } \\
\text { lesions }(\mathrm{n}=29)\end{array}$ & $\mathrm{p}$ & $\mathrm{OR}$ & $\mathrm{RR}$ \\
\hline HCMV & $22(70.96 \%)$ & $7(24.13 \%)$ & $<0.001$ & 7.68 & 2.61 \\
EBV & $13(41.93 \%)$ & 0 & $<0.001$ & - & - \\
HCMV/EBV & $11(35.48 \%)$ & 0 & $<0.001$ & - & - \\
\hline
\end{tabular}

Table 3. PCR herpesvirus detection in large and small symptomatic lesions

\begin{tabular}{llllll}
\hline Herpesvirus & $\begin{array}{l}\text { Large } \\
\text { symptomatic } \\
\text { lesions }(\mathrm{n}=23)\end{array}$ & $\begin{array}{l}\text { Small } \\
\text { symptomatic } \\
\text { lesions }(\mathrm{n}=8)\end{array}$ & $\mathrm{p}$ & $\mathrm{OR}$ & $\mathrm{RR}$ \\
\hline $\mathrm{HCMV}$ & $21(91.30 \%)$ & $1(12.5 \%)$ & $<0.001$ & 73.50 & 4.36 \\
EBV & $12(52.17 \%)$ & $1(12.5 \%)$ & 0.05 & 7.64 & 1.51 \\
HCMV/EBV & $10(43.48 \%)$ & $1(12.5 \%)$ & 0.115 & 5.38 & 1.40 \\
\hline
\end{tabular}

Table 4. PCR herpesvirus detection in large and small asymptomatic lesions

\begin{tabular}{llllll}
\hline Herpesvirus & $\begin{array}{l}\text { Large } \\
\text { asymptomatic } \\
\text { lesions }(\mathrm{n}=18)\end{array}$ & $\begin{array}{l}\text { Small } \\
\text { asymptomatic } \\
\text { lesions }(\mathrm{n}=11)\end{array}$ & $\mathrm{p}$ & $\mathrm{OR}$ & $\mathrm{RR}$ \\
\hline HCMV & $7(38.88 \%)$ & 0 & $<0.05$ & - & - \\
EBV & 0 & 0 & - & - & - \\
HCMV/EBV & 0 & 0 & - & - & - \\
\hline
\end{tabular}

\section{Discussion}

Numerous data in the literature refer to the role of herpesviruses in the pathogenesis of symptomatic periapical pathoses [15]. Activation of herpesviruses can induce significant immunosuppressive and immunomodulating ef- 
fects in the periapical area. Observations of active HCMV and EBV infections in periapical lesions may help to explain the different pathological characteristics of these inflammatory processes.

Herpesviruses can cause a series of responses involving the dysregulation of the host macrophages and lymphocytes, which substantially worsen their major role in antigen presentation [16]. This way, they can disrupt the antiviral immune response of the host [17]. HCMV has the ability to inhibit the expression of the macrophage surface receptors for the lipopolysaccharides, which can enhance Gram-negative bacterial infection [18]. Reactivation of the latent herpesviruses can occur spontaneously, or during a period of a poor host defense as a result of immunosuppression, infection, physical trauma, hormonal changes, etc. [19]. Perhaps not coincidentally, many factors that activate herpesviruses are also known risk factors for periapical deterioration $[20,21]$. The findings of Sabeti et al. [22] are consistent with the observation that various factors of virus activation are risk indicators of acute exacerbation of chronic periapical lesions.

In the study by Ozbek and Ozbek [23], HCMV DNA was found in $22.2 \%$ of apical abscess lesions, EBV DNA in $11.1 \%$, human papillomavirus DNA in $4.4 \%$ and HCMV/EBV dual infection in $4 \%$ of the lesions. Slots et al. [19] found that $100 \%$ of symptomatic periapical lesions showed the presence of an HCMV transcript. The fact that HCMV was detected as a single infection in $24 \%$ of all the periapical lesions while no lesions had EBV monoinfection shows that the HCMV endodontic pathogen is perhaps more important. A study by Sabeti and Slots [24] described only one periapical lesion showing EBV monoinfection, while Sabeti et al. [25] found HCMV active infection in $92 \%$ and EBV infection in $62 \%$ of symptomatic periapical lesions. Approximately the same ratio of these two viruses was found by Yildirim et al. [26], who examined the presence of herpesvirus in periapical lesions of deciduous teeth. Their results show that HCMV was present in $58 \%$ of the cases, while EBV was present in $62 \%$ of periapical lesions. However, in the study of Hernádi et al. [10], EBV was the predominant pathogen. The authors showed that $72.5 \%$ of periapical lesions had EBV, and HCMV was reported in only $10 \%$ of the cases. According to Verdugo et al. [27], the low HCMV prevalence in their study could be partly explained by the fact that study patients had no active periodontal disease and were following maintenance protocols.

The present study demonstrated a significantly higher frequency of HCMV infection in symptomatic compared to asymptomatic lesions. Similarly, the occurrence of
EBV infection was observed in symptomatic periapical lesions, whereas none of the asymptomatic lesions showed the presence of the EBV genome. Regarding the size of the lesions, herpesvirus infection was detected in both large symptomatic and large asymptomatic lesions. These results are consistent with the results of other authors who found that the incidence of herpesvirus was more common in symptomatic and large lesions, where the predominant pathogen was HCMV [19, 24, 25, 28]. A strong statistical correlation was identified between HCMV and EBV productive infection in symptomatic periapical lesions in the study by Slots et al. [19]. According to them, the reactivation of latent herpesvirus is involved in the maintenance of pathological processes in some types of symptomatic periapical disease.

The occurrence of dual HCMV/EBV infection in some samples was an important result of this study. The analysis showed that all lesions with dual infections were symptomatic: 9 large and 1 small. These results are consistent with the results of Sabeti et al. [29] who have shown the combined findings of HCMV/EBV productive infection in all five examined periapical lesions. The lesions were relatively large, $8 \times 12 \mathrm{~mm}$ or more in radiographic size. Predominance of HCMV/EBV genome was previously detected in symptomatic periapical lesions, $5 \times 7 \mathrm{~mm}$ or more in diameter [25]. HCMV and EBV may have a pathogenic role in severe cases of endodontic diseases. Detection of HCMV/EBV dual infection in $76 \%$ of symptomatic periapical lesions indicates the importance of the herpesvirus interactions in endodontic infections [19]. HCMV reactivation has the potential to transactivate EBV and thus create increased pathogenicity of its mechanism [30]. HCMV/EBV dual infection can cause the development of severe pathoses, as inferred from nonoral diseases, oral ulcers and marginal periodontitis [31-33]. HCMV infects mainly macrophages and T lymphocytes, whereas EBV infects B lymphocytes and tonsillar epithelial cells [9]. High levels of inflammatory cells that have a latent herpesvirus, in combination with compromised host response in periapical lesions, may create favorable conditions for its reactivation [29]. The cumulative effect of endodontic bacteria, herpesviruses and immune-mediated tissue destruction, all with the general weakening of the host defense, establishes a vicious cycle and makes periapical disease much more aggressive.

Verdugo et al. [34] examined specific herpesviral-bacterial coinfection in established peri-implantitis lesions. The higher EBV prevalence in peri-implantitis lesions versus saliva or healthy implant sites underscores the potential viral etiological importance. According to that, 
EBV may be a likely candidate in the etiopathogenesis of peri-implant disease.

Sabeti et al. [29] examined the role of HCMV and EBV in the etiology and pathogenesis of symptomatic periapical lesions of intact teeth. Since the presence of herpesviruses in periapical lesions was shown, the authors concluded that HCMV probably did not originate from the mouth. According to a study by Rosaline et al. [35], HCMV, EBV and HSV were not present in the pulp tissue of teeth with irreversible pulpitis. This can mean that herpesviruses in periapical lesions, detected in a number of studies, do not reach the periapical tissues from the oral cavity through the pulp.

The study by Andric et al. [7] showed the presence of HCMV in the walls of odontogenic cysts, periapical cysts and odontogenic keratocysts, and more than $50 \%$ of HCMV-positive odontogenic cysts in their study had a relatively high frequency of virus detection. Bearing in mind the etiology and primary pathogenic differences between periapical cysts and odontogenic keratocysts, nearly the same frequency of HCMV detection in both types of cysts was a significant result of this study. A similar percentage of HCMV-positive periapical cysts and odontogenic keratocysts suggests that HCMV probably does not play a significant role in the etiology of these cysts, but does affect their behavior during inflammation. Since it has been proven that peripheral monocytes and macrophages are the main latent HCMV infection site, and macrophages represent a significant part of the inflammatory cell infiltrate in periapical lesions, it can be assumed that the presence of HCMV in a cystic wall is the result of its infected macrophage infiltration. HCMV was detected more frequently in the samples collected from the cysts of patients who reported previous episodes of infection.

Since the monocytes and lymphocytes are migrating in the periapical sites as the first line of defense, there is a possibility that potentially infected B lymphocytes arrive into this region. Latently infected B cells can occasionally be stimulated to reactivate EBV. This produces a virus that can reinfect new B cells and epithelial cells, becoming a source of viral transmission. Reactivation could occur when latently infected $B$ cells respond to unrelated infections [36]. Waldeyer's tonsillar ring as EBV's main reservoir can potentially shed virions into saliva and the bloodstream at a continuous pace in healthy carriers. Saliva EBV levels can be replaced in as little as $2 \mathrm{~min}$ and could act as a fine vehicle to transport virus and other pathogens to different locations in the oral cavity [9].

PCR detection of herpesvirus has some limitations that must be taken into account when discussing the re- sults of this study. The high sensitivity of PCR can be misleading when it comes to the diagnosis of clinically significant herpesvirus infections. PCR detection of active viral replication becomes a possible problem for detection of latently infected periapical area. These findings may reflect only the transient differentiation of monocytes circulating in peripheral macrophages, a process which initiates the reactivation of latent viruses and which can be expected in the exacerbation of inflammatory response [7]. As this study has identified the active herpesvirus infection, it is not known whether the PCRnegative periapical areas contain viruses in the latent stage.

The fact that it is still not clear whether the activation of the herpesvirus is the cause or if it occurs secondary to acute inflammation makes this an important research goal. Most likely, there is a two-way interaction between the virus and acute inflammation. With the active herpesvirus infection there is a possibility of inducing the production of inflammatory mediators of inflammation, which have the potential for propagation of inflammation and further activation of the virus. Changes between prolonged periods of herpesvirus latency broken by periods of activation may partially explain sudden and sometimes symptomatic episodes of periapical disease. Frequent reactivation of periapical herpesvirus can accelerate the development of periapical defects, while the absence of herpesvirus infection or virus reactivation may be the reason why some periapical lesions remain clinically stable for a longer period of time [29].

Based on numerous studies that have analyzed the relationship between the detection of herpesvirus in periapical lesions and clinical characteristics of apical periodontitis, different hypotheses have been made about their role in the pathogenesis of these chronic processes [15]. The findings of Slots et al. [37] showed that herpesviruses are involved in the pathogenesis of apical periodontitis as a direct result of viral infection or virally induced irregularities of the local host defense which favors the growth of bacteria. However, the interpretation of Ferreira et al. [38, 39] suggests that the occurrence of herpesvirus may be just an epiphenomenon of bacterial infection that causes inflammation of periapical tissue with a consequent influx of virally infected inflammatory cells in the periapical region.

Since the results of several studies indicate that the etiopathogenesis of periapical lesions includes herpesvirus, Slots et al. $[19,37]$ argue that new directions for apical periodontitis prevention and treatment should focus on the control of viral pathogens. It is possible to achieve 
this effect by using systemic antiviral therapy. A study of Sunde et al. [40] suggested that virus screening and subsequent antiviral therapy may be useful as an adjunct to conventional periodontal therapy. The use of strong local antiviral root canal irrigants, sodium hypochlorite and iodine, may also be helpful in endodontic treatment of periapical pathoses.

Detection of HCMV and EBV in the samples of periapical lesions suggests an important role of herpesviruses in periapical tissue destruction. HCMV infections were more frequent in symptomatic lesions compared to asymptomatic lesions. The incidence was higher in large symptomatic lesions. EBV infection has occurred only in symptomatic lesions, in most cases in large lesions, while the dual HCMV/EBV infection has occurred only in symptomatic lesions.

\section{Acknowledgement}

This work was supported by the grant No. 175075 of the Serbian Ministry of Science.

\section{Disclosure Statement}

The authors declare that they have no conflict of interest.

\section{References}

1 Márton IJ, Kiss C: Protective and destructive immune reactions in apical periodontitis. Oral Microbiol Immunol 2000;15:139-150.

2 Nair PNR: Pathogenesis of apical periodontitis and the causes of endodontic failures. Crit Rev Oral Biol Med 2004;15:348-381.

3 Stashenko P: Role of immune cytokines in the pathogenesis of periapical lesions. Endod Dent Traumatol 1990;6:89-96.

4 Marton IJ, Kiss C: Characterization of inflammatory cell infiltrate in dental periapical lesions. Int Endod J 1993;26:131-136.

5 Lukic A, Danilovic V, Petrovic R: Comparative immunohistochemical and quantitative analysis of inflammatory cells in symptomatic and asymptomatic chronic periapical lesions (in Serbian). Vojnosanit Pregl 2008;65: 435-440.

6 Liapatas S, Nakou M, Rontogianni D: Inflammatory infiltrate of chronic periradicular lesions: an immunohistochemical study. Int Endod J 2003;36:464-471.

7 Andric M, Milasin J, Jovanovic T, Todorovic L: Human cytomegalovirus is present in odontogenic cysts. Oral Microbiol Immunol 2007;22:347-351.

8 Contreras A, Umeda M, Chen C, Bakker I, Morrison JL, Slots J: Relationship between herpesviruses and adult periodontitis and periodontopathic bacteria. J Periodontol 1999;70:478-484.

9 Hadinoto V, Shapiro M, Chi Sun C, ThorleyLawson DA: The dynamics of EBV shedding implicate a central role for epithelial cells in amplifying viral output. PloS Pathog 2009;5: $1-15$.

10 Hernádi K, Szalmas A, Mogyorosi R, Czompa L, Veress G, Csoma E, Marton I, Konya J: Prevalence and activity of Epstein-Barr virus and human cytomegalovirus in symptomatic and asymptomatic apical periodontitis lesions. J Endod 2010;36:1485-1489.
11 Siquiera JF Jr, Rôças IN: PCR methodology as a valuable tool for identification of endodontic pathogens. J Dent 2003;31:333-339.

12 Aitken C, Sengupta SK, Aedes C, et al: Heterogeneity within the Epstein-Barr virus nuclear antigen 2 gene in different strains of EpsteinBarr virus. J Gen Virol 1994;75:95-100.

13 Parra B, Slots J: Detection of human viruses in periodontal pockets using polymerase chain reaction. Oral Microbiol Immunol 1996;11: 289-293.

14 Meyer-König U, Haberland M, von Laer D, et al: Intragenic variability of human cytomegalovirus glycoprotein B in clinical strains. J Infect Dis 1998;177:1162-1169.

15 Jakovljevic A, Andric M: Human cytomegalovirus and Epstein-Barr virus in etiopathogenesis of apical periodontitis: a systematic review. J Endod 2014;40:6-15.

16 Michelson S: Human cytomegalovirus escape from immune detection. Intervirology 1999 42:301-307.

17 Boeckh M, Nichols WG: Immunosuppressive effects of beta-herpesviruses. Herpes 2003; 10: $12-16$.

18 Hopkins HA, Monick MM, Hunninghake GW: Cytomegalovirus inhibits CD14 expression on human alveolar macrophages. J Infect Dis 1996;174:69-74.

19 Slots J, Nowzari H, Sabeti M: Cytomegalovirus infection in symptomatic periapical pathosis. Int Endod J 2004;37:519-524.

20 Walton R, Fouad A: Endodontic interappointment flare-ups: a prospective study of incidence and related factors. J Endod 1992; 18:172-177.

21 Imura N, Zuolo ML: Factors associated with endodontic flare-ups: a prospective study. Int Endod J 1995;28:261-265.

22 Sabeti M, Simon JH, Slots J: Cytomegalovirus and Epstein-Barr virus are associated with symptomatic pariapical pathosis. Oral Microbiol Immunol 2003;18:327-328.
23 Ozbek A, Ozbek SM: Detection of herpesviruses and human papillomavirus in acute apical abscesses by real-time PCR. Clin Oral Invest 2015;19:343-347.

24 Sabeti M, Slots J: Herpesviral-bacterial coinfection in periapical pathosis. J Endod 2004 30:69-72.

25 Sabeti M, Valles Y, Nowzari H, Simon JH, Keramani-Arab V, Slots J: Cytomegalovirus and Epstein-Barr virus DNA transcription in endodontic symptomatic lesions. Oral Microbiol Immunol 2003;18:104-108.

26 Yildirim S, Yapar M, Kubar A, Slots J: Human cytomegalovirus, Epstein-Barr virus and bone resorption-inducing cytokines in periapical lesions of deciduous teeth. Oral Microbiol Immunol 2006;21:107-111.

27 Verdugo F, Castillo A, Simonian K, Castillo F, Farez-Vidal E, D'Addona A: Periodontopathogen and Epstein-Barr virus-associated periapical periodontitis may be the source of retrograde infectious peri-implantitis. Clin Implant Dent Relat Res 2015;17:199-207.

28 Yazdi KA, Sabeti M, Jabalameli F, Eman eini M, Kolahdouzan SA, Slots J: Relationship between human cytomegalovirus transcription and symptomatic apical periodontitis in Iran. Oral Microbiol Immunol 2008;23:510-514.

29 Sabeti M, Simon JH, Nowzari H, Slots J: Cytomegalovirus and Epstein-Barr virus active infection in periapical lesions of teeth with intact crowns. J Endod 2003;29:321-323.

30 Aalto SM, Linnavuori K, Peltola H, Vuori E, Weissbrich B, Schubert J, Hedman L, Hedman K: Immunoreactivation of Epstein-Barr virus due to cytomegalovirus primary infection. J Med Virol 1998;56:186-191.

31 Chalabi M, Moghim S, Mogharehabed A, Najafi F, Rezaie F: EBV and CMV in chronic periodontitis: a prevalence study. Arch Virol 2008;153:1917-1919. 
32 Chen V, Chen Y, Li H, Kent K, Baumgartner JC, Machida CA: Herpesviruses in abscesses and cellulitis of endodontic origin. J Endod 2009;35:182-188.

33 Slots J: Herpesviruses in periodontal diseases. Periodontol 2000 2005;38:33-62.

34 Verdugo F, Castillo A, Castillo F, Uribarri A: Epstein-Barr virus associated peri-implantitis: a split-mouth study. Clin Oral Invest 2015; 19:535-543.
35 Rosaline H, Satish ES, Kandaswamy D: Detection of presence or absence of herpes simplex virus, Epstein Barr virus and human cytomegalovirus in infected pulp using a polymerase chain reaction. Aust Endod J 2009;35: 9-12.

36 Odumade OA, Hogquist KA, Balfour HH Jr: Progress and problems in understanding and managing primary Epstein-Barr virus infectons. Clin Microbiol Rev 2011;24:193-209.

37 Slots J, Sabeti M, Simon JH: Herpesviruses in periapical pathosis: an etiopathogenic relationship? Oral Surg Oral Med Oral Pathol Oral Radiol Endod 2003;96:327-331.
38 Ferreira DC, Rochas IN, Paiva SS, Carmo FL, Cavalcante FS, Rosado AS, Santos KR, Siquiera JF: Viral-bacterial associations in acute apical abscesses. Oral Surg Oral Med Oral Pathol Oral Radiol Endod 2011;112:264-271.

39 Ferreira DC, Paiva SS, Carmo FL, Rochas IN, Rosado AS, Santos KR, Siquiera JF: Identification of herpesvirus 1 to 8 and human papillomavirus in acute apical abscesses. J Endod 2011;37:10-16

40 Sunde PT, Olsen I, Enersen M, Grinde B: Patient with severe periodontitis and subgingival Epstein-Barr virus treated with antiviral therapy. J Clin Virol 2008;42:176-178. 